Revue bibliographique pour le domaine irano-aryen

\title{
A Zoroastrian Liturgy. The Worship in Seven Chapters (Yasna 35-41). Wiesbaden, Harrassowitz, 2007, XIV+397p. (IRANICA, 12)
}

\section{Samra Azarnouche}

\section{(2) OpenEdition}

1 Journals

Édition électronique

URL : http://journals.openedition.org/abstractairanica/37861

DOI : 10.4000/abstractairanica.37861

ISSN : 1961-960X

Éditeur :

CNRS (UMR 7528 Mondes iraniens et indiens), Éditions de l'IFRI

Édition imprimée

Date de publication : 8 avril 2010

ISSN : 0240-8910

Référence électronique

Samra Azarnouche, «A Zoroastrian Liturgy. The Worship in Seven Chapters (Yasna 35-41).

Wiesbaden, Harrassowitz, 2007, XIV+397p. (IRANICA, 12) », Abstracta Iranica [En ligne], Volume 30 |

2010, document 194, mis en ligne le 08 avril 2010, consulté le 26 septembre 2020. URL : http://

journals.openedition.org/abstractairanica/37861; DOI : https://doi.org/10.4000/abstractairanica. 37861

Ce document a été généré automatiquement le 26 septembre 2020.

Tous droits réservés 


\title{
A Zoroastrian Liturgy. The Worship in Seven Chapters (Yasna 35-41). Wiesbaden, Harrassowitz, 2007, XIV+397p. (IRANICA, 12)
}

\author{
Samra Azarnouche
}

1 L'édition du texte du Yasna Haptaghāiti (YH), ces sept chapitres logés au cœur des soixante-douze chapitres du Yasna, avait déjà été maintes fois entreprise : J. Narten (1986), J. Kellens/E. Pirart (1988-1991) et H. Humbach (1991). Dans la préface de l'ouvrage, Almut Hintze explique le besoin d'une nouvelle publication du texte: considérant que certains arguments de J. Narten n'avaient pas eu l'impact qu'ils méritaient, elle en a donc résumé quelques-uns qu'elle a mis en regard avec les opinions divergentes des autres spécialistes, tout en y adjoignant ses propres remarques, puis des développements philologiques et linguistiques.

2 Le YH est une liturgie qui devait être récitée lors d'une cérémonie religieuse, célébrée par un groupe de fidèles rassemblés autour du feu rituel. Dans l'Avesta, le texte de cette liturgie (Y 35-41) est entouré des Gāthās, euX-mêmes situés au centre du Yasna, pourtant, comme elle l'avait déjà exposé dans son article « On the Ritual Significance of the Yasna Haptanhāiti », in Zoroastrian Ritual in Context, M. Stausberg (ed.), Leiden, Brill, 2004, pp. 291-316, A. Hintze estime que le YH est le Yasna par excellence.

On ne peut parler du YH sans en évoquer les différences ou les points communs avec les Gāthās. Si la langue, vieilavestique, est la même d'un point de vue grammatical, c'est au niveau lexical et poétique que se situent les différences. Contrairement aux Gāthās, le YH ne présente pas de mètre syllabique régulier, car le modèle rythmique est révélé par des figures stylistiques formées de petites unités en contrepoint les unes avec les autres. Ainsi, quand la forme poétique des Gāthās est gouvernée par le rythme des syllabes, celle du YH l'est par celui des mots. Cette découverte, que l'auteur attribue à J. Narten, est ce que C. Watkins appellera « the strophic style » en le mettant 
en parallèle avec d'autres traditions indo-européennes. Le YH et les Gāthās, très certainement issus de milieux différents, se distinguent aussi dans leurs intonations et leurs récitations lors de la célébration du culte. Parmi les traits rhétoriques qu'ils partagent, l'A. cite le recours à la figure de l'argument+contre argument pour désigner la totalité d'une notion (Y 35.2 : iiadacā aniiadacā «i ici et ailleurs »), ou celle de l'argument+contre argument négatif visant à intensifier un argument, telle que le ferait une litote (Y 35.2: aibīijarətārō naēnaēstārō «(we are) welcomers, not revilers »).

4 Sept chapitres composent cette vaste étude : introduction (pp. 1-28, où la structure du texte est analysée en détails); texte et traduction (29-60) ; édition et commentaires (pp.61-326, le texte et la traduction y figurent à nouveau, mais enrichis d'un solide appareil critique. Les termes commentés sont déjà annoncés dans la table des matières, ce qui en facilite l'accès); glossaire (pp.327-367, comprenant entre autres les références aux AirWb, EWAia, à l'édition de Narten, aux parallèles védiques, à l'indoeuropéen, et au moyen-perse); bibliographie (pp.369-384); enfin la liste des abréviations suivie de trois index : mots, passages cités, noms propres et notions.

5 Le YH se décompose en trois sections qui forment chacune un anneau:

1) Y 35.2-36.6: le texte s'ouvre sur la triade rituelle, saluée par les sacrifiants. Puis, en 36.1-3 le feu sacrificiel devient le feu d'Ahura Mazdā. C'est à partir de cette transsubstantiation que les fidèles se considèrent en présence du dieu. 2) Y. 37.1-39.4: l'analyse de cette partie centrale qui contient l'évocation du culte (la formule yazamaidē «nous rendons hommage » y est répétée 17 fois) est particulièrement intéressante : l'A. y met au jour 6 cercles concentriques enfermant une partie centrale, $Y$ 38.3-5 qui est la prière aux eaux, et dont le centre, Y 38.4, est l'évocation-même du culte, 3) Y 40-41: dans cette dernière partie est formulée une demande de récompense eschatologique, ainsi qu'une prière à Ahura Mazdā et à Aš̃

6 Au fur et à mesure d'une lecture détaillée des mots, des phrases et des unités poétiques du texte, A. Hintze va desceller les multiples cercles qui caractérisent la structure littéraire d'une composition en anneau. Chacune de ces trois parties contient des anneaux, formant ainsi une unité. Elles sont reliées entre elles par des «framing devices ", éléments qui les articulent de manière à créer un ensemble homogène. Cette structure littéraire fait du YH un exemple représentatif des formes liturgiques caractérisées par un discours rythmique, attestées également dans d'autres langues indo-européennes.

7 Outre l'apport considérablement innovant sur l'aspect formel et poétique d'un texte sacrificiel, cette étude érudite, dédiée à Johanna Narten, demeure un ouvrage de philologie avestique classique dont les commentaires linguistiques et grammaticaux, ainsi que les confrontations d'opinions - sans jamais glisser dans des règlements de compte - constituent une contribution de plus qu'Almut Hintze offre aux études zoroastriennes. 
INDEX

Thèmes : 6.1. Zoroastrisme

\section{AUTEURS}

SAMRA AZARNOUCHE

Paris 